\title{
Gammaherpesvirus-Induced Lung Pathology Is Altered in the Absence of Macrophages
}

\author{
J. M. Cadillac, ${ }^{1 *}$ R. E. Sigler, ${ }^{2}$ J. B. Weinberg, ${ }^{3}$ M. L. Lutzke, ${ }^{3 * *}$ and \\ R. Rochford ${ }^{4}$
}

\footnotetext{
${ }^{1}$ Unit for Laboratory Animal Medicine, University of Michigan, Ann Arbor, Michigan 48109, USA; ${ }^{2}$ Esperion Therapeutics, Inc., 3621 S. State St., 695 KMS Place, Ann Arbor, Michigan 48108, USA; ${ }^{3}$ Division of Pediatric Infectious Diseases, University of Michigan, Ann Arbor, Michigan 48109, USA; ${ }^{4}$ Department of Microbiology and Immunology, SUNY Upstate Medical University, 750 East Adams St., Syracuse New York 13210, USA
}

Abstract. The purpose of this study was to examine the lung pathogenesis of murine gammaherpesvirus (MHV-68) infection in mice that lack $\mathrm{CC}$ chemokine receptor CCR2, an important receptor for macrophage recruitment to sites of inflammation. BALB/c and $\mathrm{CCR} 2^{-/-}$mice were inoculated intranasally (i.n.) with MHV-68 and samples were collected during acute infection (6 dpi) and following viral clearance (12 dpi). Immunohistochemistry was used to determine which cells types responded to MHV-68 infection in the lungs. Lung pathology in infected BALB/c mice was characterized by a mixed inflammatory cell infiltrate, necrosis, and increased alveolar macrophages by $12 \mathrm{dpi}$. Immunohistochemistry showed intense positive staining for macrophages. $\mathrm{CCR}^{-/-}$mice showed greater inflammation in the lungs at $12 \mathrm{dpi}$ than did $\mathrm{BALB} / \mathrm{c}$ mice, with more necrosis and diffuse neutrophil infiltrates in the alveoli. Immunohistochemistry demonstrated much less macrophage infiltration in the $\mathrm{CCR} 2^{-/-}$mice than in the $\mathrm{BALB} / \mathrm{c}$ mice. These studies show that $\mathrm{CCR} 2$ is involved in macrophage recruitment in response to MHV-68 infection and illustrates how impairments in macrophage function affect the normal inflammatory response to this viral infection.

Key words: Macrophage_Lung_-Gammaherpesvirinae/pathogenicity—Disease models, animal-Chemokines.

${ }^{*}$ Current address: Laboratory Animal Health Sciences, The Jackson Laboratory, 600 Main St., 


\section{Introduction}

The lung is often the site of entry for viruses because of the large bronchial and alveolar surface area. Although many viral infections are rapidly resolved, evidence is accumulating that is a subset of viral infections is associated with chronic lung disease. For example, herpesvirus infections have been shown to be associated with the development of idiopathic pulmonary fibrosis [33] and primary pulmonary hypertension [7]. Understanding how viral infections induce immunopathology in the lungs is critical to development of prevention and treatment of chronic lung diseases.

Challenge of mice with a variety of respiratory viruses has proven to be a useful model system to elucidate many of the host factors involved in immune response in the lung. Infection of mice with murine gammaherpesvirus (MHV)-68 serves as a model to study the effects of viral infection on lung pathology. MHV-68 is a naturally occurring rodent pathogen which, following intranasal (i.n.) inoculation in mice, replicates in the lungs [1, 5, 22, 24, 27, 29, 31, 32]. Viral latency is established predominantly in the mediastinal lymph nodes (MLN) and in the spleen [5, 29], but there is also evidence that viral DNA can persist in the lungs of infected mice $[28,37]$ suggesting that this virus could also contribute to a sustained immune response in the lungs.

Chemokines are chemotactic cytokines that orchestrate the movement of leukocytes along a concentration gradient into and out of sites of inflammation $[18,25,34]$. They are increasingly recognized as key mediators of inflammation and leukocyte recruitment in response to inflammatory stimuli including viral infections $[18,25]$. Viral respiratory infection induces the production of chemokines critical to the host inflammatory response $[9,10,13,20,36]$.

Early descriptions of lung inflammation following MHV-68 infection noted cellular infiltrates lasting up to 30 days post inoculation (dpi) $[2,30]$. We and others have described a sustained chemokine response, including monocyte chemoattractant protein-1 (MCP-1), to lung infection with MHV-68 [26, 38] suggesting that these chemokines contribute to lung inflammation. Chemokine receptors are expressed on a number of cells, including monocytes, macrophages, T lymphocytes, eosinophils, and basophils [18]. MCP-1, now termed chemokine ligand 2 [35, 39], and its receptor CCR2 are potent monocyte and lymphocyte chemoattractants important in the pathogenesis of several inflammatory diseases, including atherosclerosis, idiopathic pulmonary fibrosis, and multiple sclerosis $[8$, 15-18]. Deficiency of CCR2 results in delayed or failed macrophage recruitment, which in turn causes a reduction in phagocytosis with prolonged influx of and/or increased numbers of neutrophils and eosinophils and resultant tissue damage [4, $8,15,16]$.

To determine the role of macrophages in MHV-68 infection of the lung, $\mathrm{BALB} / \mathrm{c}$ and $\mathrm{CCR} 2^{-/-}$mice were infected with MHV-68 and examined histologically. The kinetics of pathologic lesions in the lungs following MHV-68 infection is described. Our data suggest that MHV-68 infection is a useful model for viral-induced pathology in the lungs and that in the absence of CCR2 there is increased inflammation. 


\section{Materials and Methods}

\section{Animals}

Four-six-week-old male BALB/c mice were purchased from Harlan Sprague Dawley, Inc. (Indianapolis, IN). Six-eight-week-old CCR2 $2^{-/-}$mice $\left(\mathrm{BALB} / \mathrm{cCmkbr} 2^{\mathrm{tm} 1 \mathrm{Kuz}}\right.$ ) of both genders were a kind gift from Dr. Gary Hufmagle (University of Michigan, Ann Arbor, MI). All mice were maintained in specific-pathogen-free housing and acclimated in the animal facility for 4-7 days before infection occurred. The mice were housed in accordance with Animal Welfare Act regulations and the Guide for the Care and Use of Laboratory Animals, under a protocol approved by the University of Michigan Committee on Use and Care of Animals.

\section{Virus Infection}

Generation of MHV-68 stocks was done as previously described [5]. Mice were lightly anesthetized with isoflurane (AErrane ${ }^{\circledR}$; Baxter, Deerfield, IL) and inoculated i.n. with $4 \times 10^{4}$ plaque-forming units (PFUs) of virus, diluted in $20 \mu \mathrm{l}$ of sterile phosphate buffered saline (PBS; GibcoBRL, Grand Island, NY). Control mice (mock infected) were inoculated with $20 \mu \mathrm{l}$ of supernatant from mock virus preparation at an equivalent dilution in PBS. BALB/c and $\mathrm{CCR}^{-/-}$mice were euthanized with isoflurane at 6 and $12 \mathrm{dpi}$. Additional BALB/c mice were also euthanized at 16, 20, and $31 \mathrm{dpi}$.

\section{Ribonuclease Protection Assay}

RNA was extracted from tissues as described [6, 24]. MHV-68 gene expression was determined using the $\gamma-7$ riboprobe template, as previously described [24]. All riboprobe syntheses were driven by T7 bacteriophage RNA polymerase with $\left[\alpha{ }^{32}\right.$ P]UTP (Amersham, Arlington Heights, IL) as the labeling nucleotide [14]. The ribonuclease protection assay (RPA) was done as described [24]. Bands were visualized by autoradiography (XAR film, Kodak, Rochester, NY) and were quantified by using the Storm PhosphorImager and ImageQuant software (Molecular Dynamics, Sunnyvale, CA). Volume measurements with rectangular objects were used to generate PhosphorImager (PI) counts, which are presented as a percentage of the internal housekeeping gene signal (i.e., L32) present in each lane.

\section{Histopathology}

The left lung was resected, inflated with O.C.T. (Tissue-Tek, Torrance, CA), placed in freezing embedding medium (O.C.T.), and snap-frozen on dry ice with ethyl alcohol. Frozen tissue was stored at $-80^{\circ} \mathrm{C}$ until sectioning. Serial sections, 4-8 $\mu \mathrm{m}$ thick, were stained with hematoxylin and eosin (H\&E) or prepared for immunohistochemistry.

Upon initial blind evaluation of slides, it was determined that histology findings in uninfected and mock-infected mice were identical. In both groups, lungs demonstrated minimal focal or no inflammation and no necrosis or hemorrhage. Consequently, for comparison purposes, lung histology in these two groups was considered as baseline regarding subsequent evaluation and scoring of infected mice. A score of 0 reflects no remarkable change. A score of 1 indicates a minimal increase in cells or observation of necrosis in at least two locations. A score of 2 indicates a mild increase in cell numbers, with at least three inflammatory cells per high-powered field and/or at least three necrotic cells near a given airway or vessel. A score of 3 indicates moderate inflammation, with a large contiguous population of cells ( $30+$ cells $)$ and/ or areas of necrosis with at least ten necrotic cells near a given airway or vessel. A score of 4 indicates marked inflammation, with a high number of inflammatory cells forming clumps, filling the alveoli. 
Immunohistochemistry was used to determine which cells responded to MHV-68 infection in $\mathrm{BALB} / \mathrm{c}$ and $\mathrm{CCR} 2^{-/-}$mice. Cryosections were air-dried for $1-2$ hours, fixed in acetone at $4^{\circ} \mathrm{C}$ for 15 minutes, allowed to air dry again, and then stored at $-80^{\circ} \mathrm{C}$ [11]. Immunohistochemistry was performed using the Elite ABC Kit (Vector Laboratories, Burlingame, CA) according to the manufacturer's protocol with several modifications. Buffer of $0.1 \%$ saponin in $1 \times \mathrm{PBS}$ with $500 \mathrm{mM} \mathrm{NaCl}$ was used throughout the protocol. Sections were incubated with a $1 \% \mathrm{H}_{2} \mathrm{O}_{2}$ in $\mathrm{CH}_{3} \mathrm{OH}$ to block endogenous peroxidase activity. Sections were then treated with an avidin-biotin blocking complex (Vector Laboratories), followed by a blocking step using $5 \%$ bovine serum albumin (BSA, Vector Laboratories). The primary antibody and controls were then applied and incubated overnight at $4^{\circ} \mathrm{C}$. Four $15-$ minute washes in buffer were performed, followed by application of the diluted biotinylated secondary antibody solution for 20 minutes. Primary antibodies included antimurine Mac3, Mac1- $\alpha$, CD16/ CD32, which were all purchased from PharMingen (San Diego, CA); and MOMA-2, which was purchased from Serotec (Oxford, UK). Mac3, clone M3/84 detects immature monocytes and macrophages. Mac1- $\alpha$, clone CD11b (M1/70) detects granulocytes, macrophages, dendritic cells (DC), and natural killer (NK) cells. CD16/CD32 detects NK cells, granulocytes, most T cells, monocytes and macrophages, mast cells, B lymphocytes, and DC cells (at low levels). Rat $\operatorname{IgG}_{2 \mathrm{a}}$ isotype, clone R35-95 (PharMingen) was used for a control antibody. MOMA-2 detects mouse monocytes and macrophages and rat IgG2b (Serotec) was used for a control antibody. Normal BALB/c mouse serum was a kind gift from Dr. Jean Nemzek (University of Michigan, Ann Arbor, MI).

\section{Statistics}

Group means were compared by two-sample $t$-test. Statistical significance was set at $p<0.05$.

\section{Results}

\section{Lung Pathology in BALB/c Mice Infected with MHV-68}

To characterize the pathology of the inflammatory response to viral infection, $\mathrm{BALB} / \mathrm{c}$ mice were inoculated i.n. with MHV-68 and lungs were processed for histology or for RNA extraction at 6, 12, 16, 20, and 31 dpi. As shown in Figure 1 , a mild inflammatory response was seen during the first two evaluation time points ( 6 and $12 \mathrm{dpi}$ ). At both 6 and $12 \mathrm{dpi}$, there was a perivascular and peribronchial inflammatory pattern characterized by a mixed population of neutrophils, lymphocytes, and plasma cells, with an increased alveolar macrophage population compared with baseline (Fig. 1A, B). By 16 dpi, the perivascular and peribronchial infiltrates were the most severe (Fig. 1C). There was little hemorrhage or necrosis and no alveolar macrophage response, i.e. no continued increase in numbers of macrophages compared with baseline. At $20 \mathrm{dpi}$, the inflammatory response continued to decrease from the preceding time point, with perivascular and peribronchial infiltrates present to a lesser degree (Fig. 1D). Severity of inflammation was slightly decreased compared with that at $12 \mathrm{dpi}$. There was no increased alveolar macrophage response over baseline at this point, and there was no hemorrhage or necrosis present. By $31 \mathrm{dpi}$, the perivascular and peribronchial inflammation was still evident, but the predominant inflammatory cell types switched to lymphocytes and a few monocytes (Fig. 1E). This is consistent with subacute inflammation that classically has a preponderance of lymphocytes and 
variable numbers of monocytes [3]. There was also no alveolar macrophage response over baseline and no hemorrhage or necrosis present at $31 \mathrm{dpi}$.

To quantify the inflammatory response to the virus, H\&E-stained sections of infected lungs at $6 \mathrm{dpi}$ (peak of viral infection) and $12 \mathrm{dpi}$ (following viral clearance) were evaluated for pathology. Specific criteria were chosen to allow repeatable scoring based on counting of either inflammatory cells or hemorrhagic or necrotic foci. Slides were evaluated in six categories: (1) perivascular and peribronchial inflammation, (2) perivascular necrosis, (3) perivascular hemorrhage, (4) increased neutrophils in the alveoli, (5) increased number of alveolar macrophages, and (6) alveolar necrosis. Each slide was evaluated blindly and was scored semiquantitatively on a scale from 0 to 4 based on severity of lung pathology (see the Methods section for scoring explantation). With the exception of mean neutrophil numbers, mean scores of inflammation, necrosis, and hemorrhage increased between 6 and 12 dpi (Fig. 2A).

The lungs of infected BALB/c mice had intense positive staining for monocytes and macrophages with the macrophage markers MOMA-2 (Fig. 3A) and Mac3 (data not shown) at $6 \mathrm{dpi}$ and light positive staining by $12 \mathrm{dpi}$. These immunohistochemistry results confirm the presence of monocytes and macrophages in MHV-68 infection during both acute and recovered infection as noted by histologic analysis.

To verify viral infection of the mice, RNA was analyzed by RPA to measure expression of viral transcripts. We observed high-level viral gene expression at 6 dpi (Fig. 4) consistent with our previous observations that 6 dpi corresponds to the acute phase of viral infection in the lung [38]. No viral gene expression was observed at the later time points (Fig. 4 and data not shown) verifying that virus was cleared from the lungs by $12 \mathrm{dpi}$.

\section{Role of CCR2 in MHV-68-Induced Inflammatory Response}

CCR2 is the receptor for the monocyte chemoattractant protein-1 (MCP-1) [39]. Infection of mice deleted of CCR2 (CCR2 ${ }^{-/-}$mice) results in reduced macrophage recruitment in the lungs following viral infection [16]. To determine if the absence of CCR2 would impact the pathogenesis of MHV-68 infection, CCR2 $2^{-/}$mice were infected i.n. with MHV-68 and lungs were processed for histology or for RNA extraction. We observed a robust pattern of viral gene expression in the $\mathrm{CCR}^{-/-}$infected mice at $6 \mathrm{dpi}$ as determined by RPA analysis (Fig. 4). Viral gene expression was no longer detectable by $12 \mathrm{dpi}$ in the $\mathrm{CCR} 2^{-/-}$mice, indicating that the virus was cleared by this time point. No significant differences in the pattern of viral gene expression were observed following infection of BALB/c or CCR2 $2^{-/-}$mice (Fig. 4B).

In the $\mathrm{CCR} 2^{-/-}$infected mice, inflammation was characterized most commonly by a mixed infiltrate of neutrophils, lymphocytes, and plasma cells. Perivascular inflammation and peribronchial inflammation were minimal in CCR2 $2^{-/-}$ mice at $6 \mathrm{dpi}$ (Fig. 5A, B), and the mean score for alveolar macrophage accumulation was less than 1 (Fig. 2A). By 12 dpi, scores for all six evaluation cate- 

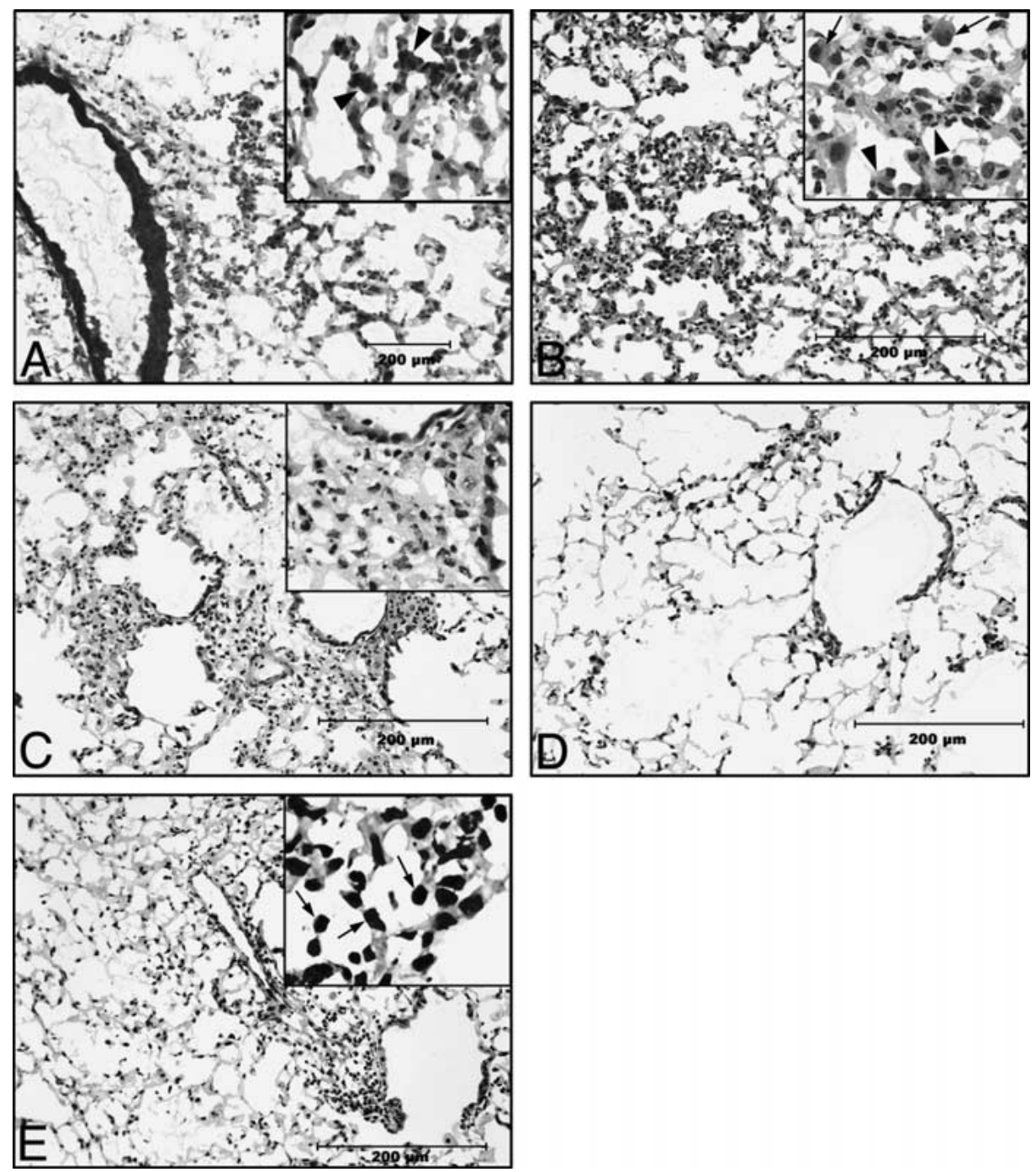

Fig. 1. Characterization of lung pathology following intranasal infection with MHV-68 in the lungs of $\mathrm{BALB} / \mathrm{c}$ mice. All sections are prepared from frozen tissue and stained with H\&E. (A) Acute infection (6 dpi) characterized by a mild mixed-cell inflammatory infiltrate which caused an increased lung cellularity; scale $=200 \mu \mathrm{m}$. Inset shows accumulation of neutrophils (arrowheads) and lymphocytes. (B) By 12 dpi, a moderate mixed-cell inflammatory response is seen with an increased alveolar macrophage population; scale $=200 \mu \mathrm{m}$. Inset shows neutrophils (arrowheads) and alveolar macrophages (arrows). (C) At $16 \mathrm{dpi}$, the mixed-cell infiltrate is most severe, characterized by multifocal dense accumulations of inflammatory cells; scale $=200 \mu \mathrm{m}$. Inset shows cellular infiltrates in the peribronchial regions. (D) By $20 \mathrm{dpi}$, the inflammatory response has greatly decreased compared with the earlier time points; scale $=200 \mu \mathrm{m}$. (E) At $31 \mathrm{dpi}$, a diffuse lymphocytic infiltrate is seen; scale $=200 \mu \mathrm{m}$. Inset shows dense accumulation of lymphocytes (arrows). Original magnifications: $\times 200$ $(\mathbf{A}-\mathbf{E})$; insets $\times 400(\mathbf{A}, \mathbf{B}, \mathbf{E}), \times 800(\mathbf{C})$. 

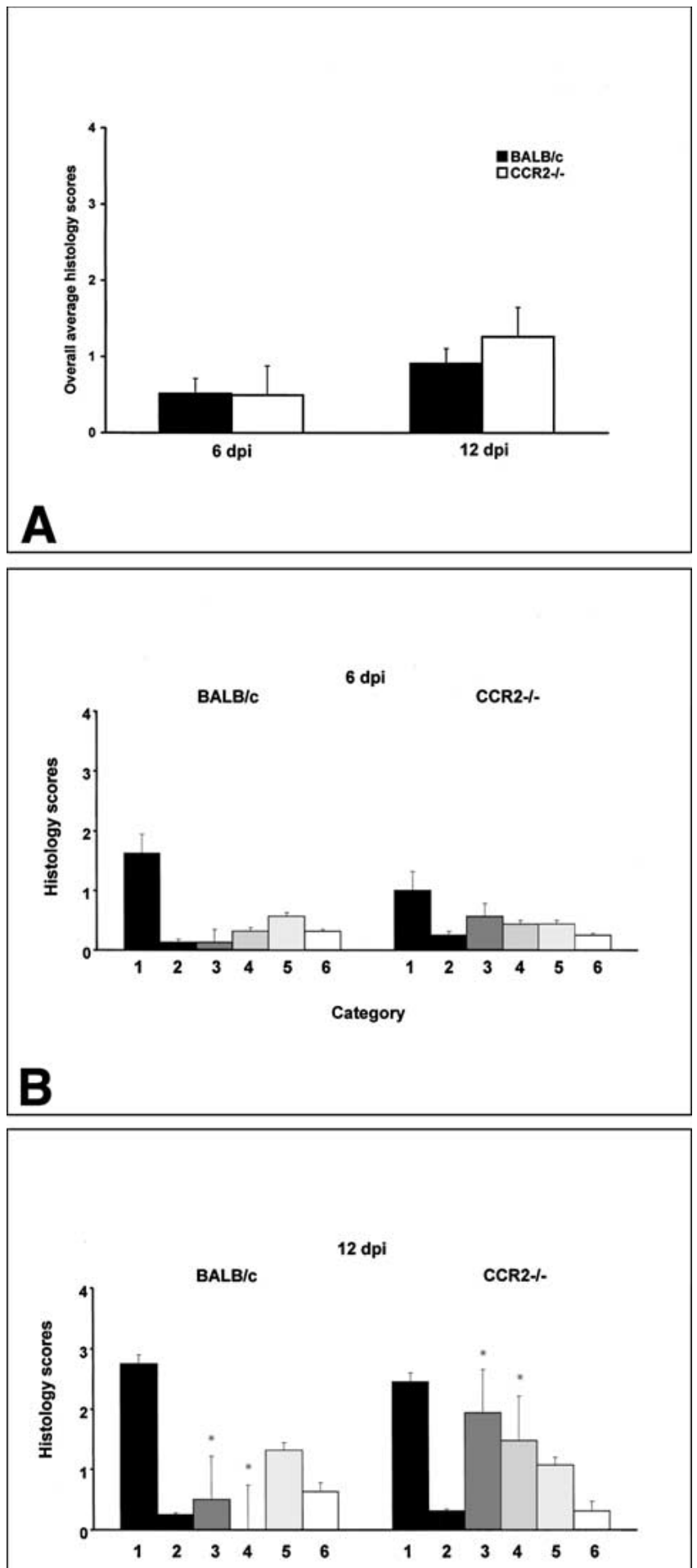

Fig. 2. Mean histology scores from lungs of BALB/c and CCR2 $2^{-/-}$ mice infected i.n. with MHV-68. (A) Overall average histology scores graded from 0 (no change) to 4 (marked inflammation). BALB/c and $\mathrm{CCR} 2^{-/-}$infected mice were compared at $6 \mathrm{dpi}$ and $12 \mathrm{dpi}$ in six categories: (B, C) Lanes 16 represent pathology categories as indicated: 1, perivascular and peribronchial inflammation; 2, perivascular necrosis; 3 perivascular hemorrhage; 4 increased neutrophils in the alveoli; 5 , increased number of alveolar macrophages; and 6, alveolar necrosis. Each 

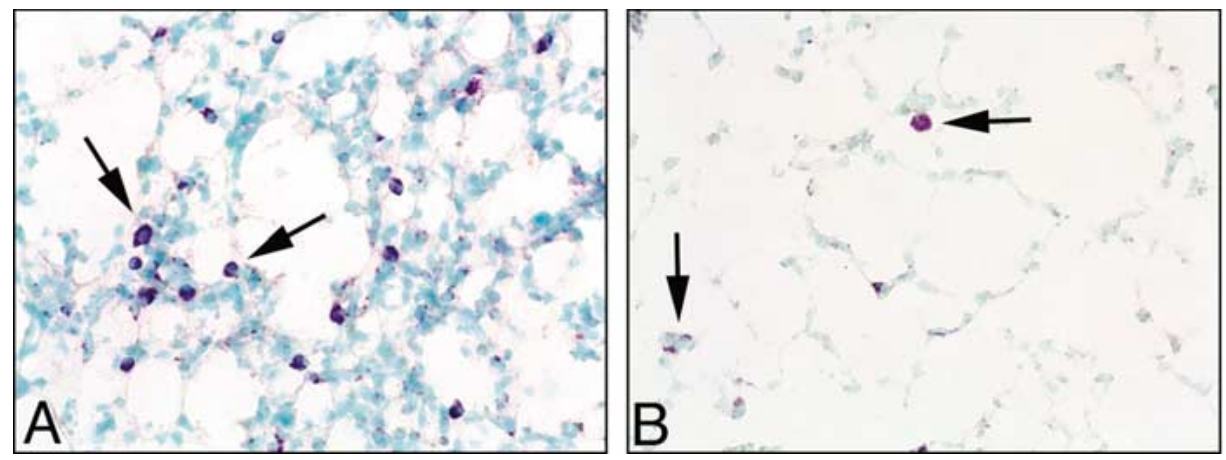

Fig. 3. Evaluation of the inflammatory response to MHV-68 infection in the lungs of BALB/c and $\mathrm{CCR}^{-/-}$mice using immunohistochemistry on frozen sections. (A) MOMA-2 positive staining of alveolar macrophages (arrows) at $6 \mathrm{dpi}$ in a BALB/c mouse, showing numerous macrophages. (B) Few macrophages are seen at $6 \mathrm{dpi}$ in a $\mathrm{CCR} 2^{-/-}$mouse, as expected with a deficiency in CCR2. Original magnifications: $\times 400$.

gories (Fig. 2C) were increased from the prior time point (Fig. 2B). Overall histology scores for $\mathrm{BALB} / \mathrm{c}$ and $\mathrm{CCR} 2^{-/-}$mice show a trend of increasing inflammation from $6 \mathrm{dpi}$ to $12 \mathrm{dpi}$. At $12 \mathrm{dpi}$ (Fig. 2C), there is a significant difference between the $\mathrm{BALB} / \mathrm{c}$ mice and the $\mathrm{CCR} 2^{-/-}$mice when comparing perivascular necrosis and diffuse alveolar neutrophil infiltrates $(p<0.05)$. $\mathrm{CCR} 2^{-/-}$mice at both time points had lower mean alveolar macrophage scores (i.e., less macrophage accumulation) when compared with $\mathrm{BALB} / \mathrm{c}$ mice.

By $12 \mathrm{dpi}$ (Fig. 5C), the CCR2 $2^{-/-}$mice showed increased perivascular necrosis and increased numbers of neutrophils in the alveoli that were significantly greater when compared with those of the BALB/c mice $(p<0.05)$. Perivascular and peribronchial regions of hemorrhage were observed in both the BALB/c and the $\mathrm{CCR} 2^{-/-}$mice, associated with regions of severe perivascular and peribronchial necrosis and inflammation. Necrosis of the alveolar epithelial cell lining was a rare finding, noted only in CCR2 $2^{-/-}$animals (one mouse at $6 \mathrm{dpi}$ and one mouse at $12 \mathrm{dpi}$.

At 6 and $12 \mathrm{dpi}$, lungs of CCR2 $2^{-/}$mice showed light positive staining for monocytes and macrophages with MOMA-2 (Fig. 3B) and Mac3 (data not shown). These results support the histologic observations that there were a decreased number of alveolar macrophages present in the $\mathrm{CCR} 2^{-/-}$mice compared with the $\mathrm{BALB} / \mathrm{c}$ mice.

Summary of Histological Findings

Inflammation, necrosis, and increases in alveolar macrophages were more severe at $12 \mathrm{dpi}$ than at $6 \mathrm{dpi}$ for both $\mathrm{BALB} / \mathrm{c}$ and $\mathrm{CCR} 2^{-/-}$mice. $\mathrm{CCR} 2^{-/-}$mice showed greater inflammation at $12 \mathrm{dpi}$ than did $\mathrm{BALB} / \mathrm{c}$ mice. This inflammation was accompanied by statistically significant higher incidence and severity of 
A
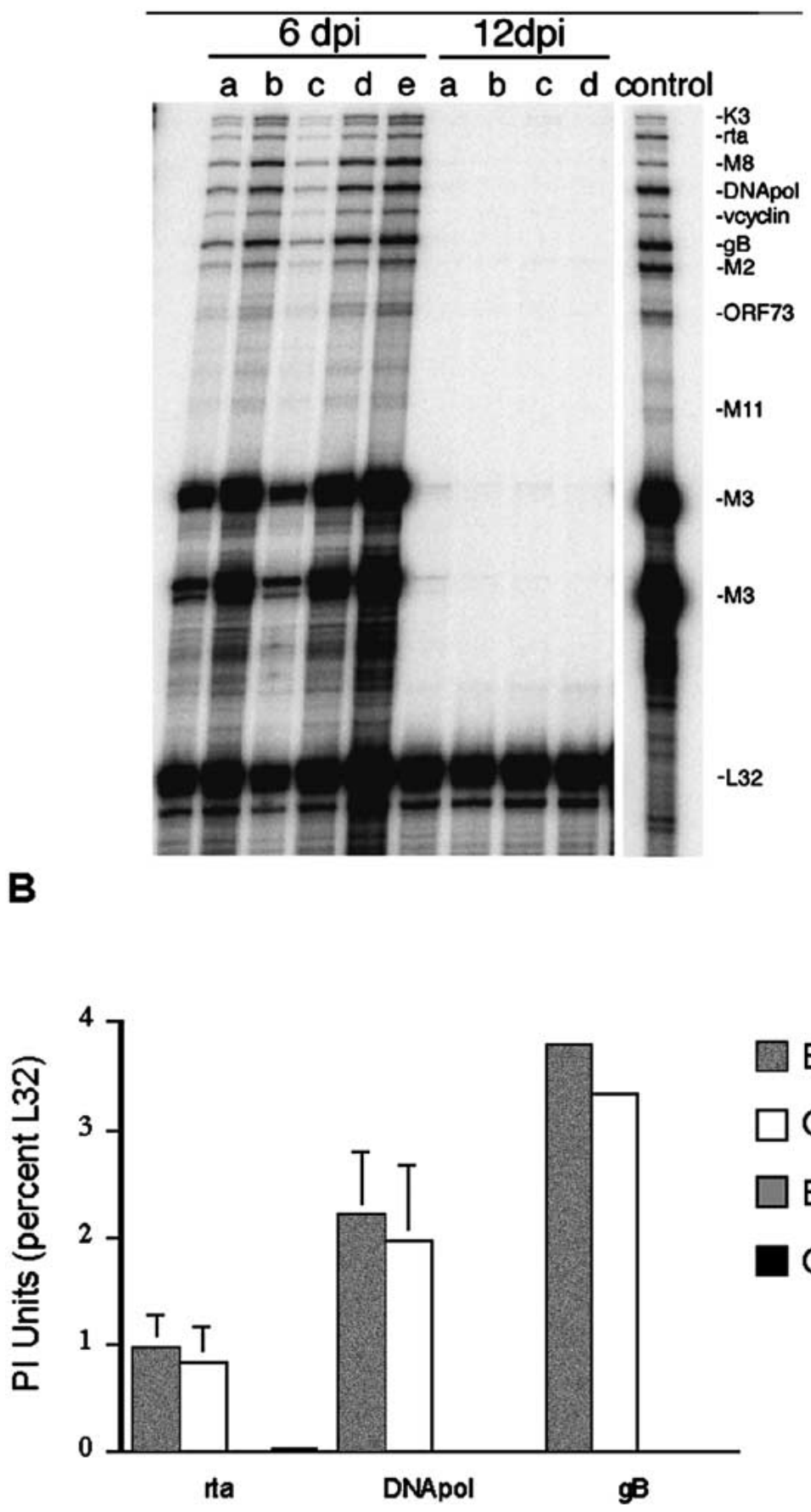

BALB/c 6 dpi

$\square$ CCR2-/- 6 dpi

$\square$ BALB/c 12 dpi

CCR2-/- 12 dpi 
Fig. 4. (A) Viral gene expression in lungs of CCR $2^{-/-}$mice infected with MHV-68. RNA was harvested at 6 and $12 \mathrm{dpi}$, and $5 \mu \mathrm{g}$ of RNA was analyzed for expression of MHV-68 transcripts by RPA with the $\gamma-7$ probe set. Shown is a representative phosphorimage. Each lane represents RNA extracted from a single mouse. (B) Quantitation of MHV-68 gene expression following infection of BALB/c or $\mathrm{CCR} 2^{-/-}$mice. PI counts were obtained for protected probe fragments and the data are presented as a percentage of the internal housekeeping signal L32. Means \pm SEM are shown for each time point for $\mathrm{balb} / \mathrm{c}$ and CCR2-/- mice.

perivascular necrosis and diffuse alveolar neutrophil infiltrates in CCR2 $2^{-/-}$mice, possibly secondary to decreased alveolar macrophage recruitment in these animals.

\section{Discussion}

MHV-68 provides a useful model system to study the pathogenesis of gammaherpesviruses and host responses to this viral infection. In this study, we have characterized the pathogenesis of MHV-68 in BALB/c and $\mathrm{CCR} 2^{-/-}$mice, focusing on the histopathologic features of infection, identification of cells involved, and the role of CCR2 involvement in macrophage recruitment during viral infection.

We found that lung pathology in BALB/c mice infected with MHV-68 was characterized by a mixed inflammatory infiltrate, necrosis, and increased alveolar macrophages by 12 dpi consistent with previous studies $[22,30]$. In many lung sections from the CCR $2^{-/-}$mice, approximately $10-15 \%$ of nuclei in perivascular regions were apoptotic. This far exceeds the expected percent of inflammatory cells which may undergo apoptosis in a typical inflammatory reaction and supports the fact that resident epithelial and stromal cells in perivascular regions are undergoing necrosis. Inflammation was still present at $30 \mathrm{dpi}$, consisting primarily of lymphocytes and a few monocytes. This contrasts with previous studies that reported only persistent areas of lymphoid cells in the lungs [22, 30]. The presence of both lymphocytes and monocytes is more typical of subacute to chronic inflammation [3, 23], suggesting that MHV-68 infection, while resolved by $12 \mathrm{dpi}$, initiates a chronic inflammatory stimulus. Recent studies show that low-level infectious MHV-68 can be isolated from the lungs greater than $30 \mathrm{dpi}$ [12] and it is possible that this low-level persistence of the virus could maintain this inflammatory stimulus.

At 6 dpi, CCR2 ${ }^{-/}$infected mice demonstrated fewer alveolar macrophages with minimal perivascular and peribronchial inflammation compared with BALB/c infected mice. By $12 \mathrm{dpi}$, the $\mathrm{CCR}^{-/-}$infected mice showed a statistically significantly higher severity of perivascular necrosis and diffuse alveolar neutrophil infiltrates and a high incidence of peribronchial necrosis. Immunohistochemistry results confirm the presence of fewer monocytes and macrophages in $\mathrm{CCR} 2^{-/-}$mice than in $\mathrm{BALB} / \mathrm{c}$ mice. This is consistent with the prolonged neutrophil response as a result of decreased phagocytosis due to delayed macrophage migration that has been reported in CCR $2^{-/-}$mice $[8,21]$. Neutrophils 

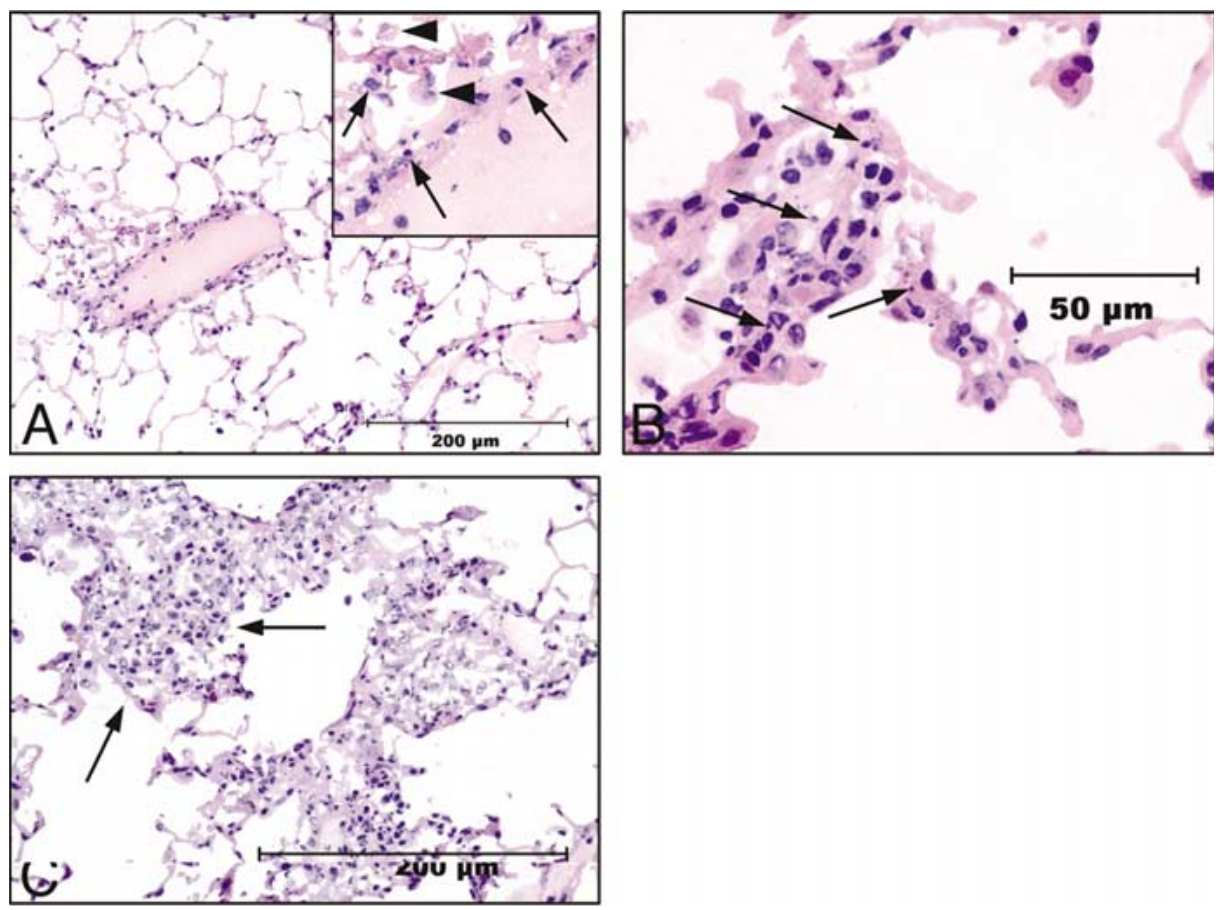

Fig. 5. Inflammatory response to MHV-68 in lungs of CCR $2^{-/-}$mice. Frozen sections were stained, with H\&E. (A) Perivascular inflammation and hemorrhage in the lungs of a CCR2 $2^{-/-}$mouse at $6 \mathrm{dpi}$, scale $=200 \mu \mathrm{m}$. Inset shows numerous lymphocytes (arrows) and alveolar macrophages (arrowheads). An area of hemorrhage is present between the two labeled macrophages. Several cells in the vessel wall are necrotic. (B) Higher magnification of a $\mathrm{CCR} 2^{-/-}$mouse at $6 \mathrm{dpi}$ showing several picnotic cells which characterize perivascular and alveolar wall necrosis (arrows); scale $=50 \mu \mathrm{m}$. There are multiple neutrophils also identified. (C) Perivascular infiltrates and necrosis in a CCR2 $2^{-1}$ mouse at $12 \mathrm{dpi}$; scale $=200 \mu \mathrm{m}$. Lung interstitium and alveolar spaces are highly cellular. Area between arrows has increased numbers of neutrophils and alveolar macrophages with numerous lymphocytes also present. Original magnifications: $\times 400$ (A, C), $\times 700$ (B).

typically are predominant in acute inflammation [3], while neutrophils, lymphocytes, and plasma cells can all be seen in subacute inflammation [3].

Altogether, these findings suggest that CCR2 is important in monocyte trafficking during inflammation and infection with MHV-68. Several investigators have shown that $\mathrm{CCR} 2^{-/-}$mice challenged immunologically with various pathogens and nonspecific inflammatory stimuli demonstrate defects in macrophage function $[8$, 15-17, 19]. These results demonstrate that macrophages are also important modulators of inflammation in this murine model of gammaherpesvirus-induced lung pathology as the lung pathology is more severe in the absence of macrophages. Understanding which cell populations are associated with the host response to viral infection in the lungs and determining the long-term effect of viral infection on chronic inflammatory responses can hopefully lead to interventions for the prevention and treatment of viral-induced lung disease. 
Acknowledgments. This work was supported in part by NIH/NCRR T32 RR07008 (J.C.), NICHD grant HD28820 (J.W.), and NIA AG908692 (R.R.). The authors would like to thank the Martin Philbert laboratory for use of their cryostat, Thomas Komorowski for his technical assistance, and Dr. Ken Guire, University of Michigan, and Dr. Weidong Zhang, The Jackson Laboratory, for advice on statistical analysis. The authors also thank Elizabeth Horn and Mark Deming from Pathology Photography for their technical assistance. The authors are especially grateful to the personnel at Diane Robins Laboratory for their support.

\section{References}

1. Blaskovic D, Stancekova M, Svobodova J, Mistrikova J (1980) Isolation of five strains of herpesviruses from two species of free living small rodents. Acta Virol 24:468

2. Blaskovic D, Stanekova D, Rajcani J (1984) Experimental pathogenesis of murine herpesvirus in newborn mice. Acta Virol 28:225-231

3. Bochsler PN, Slauson DO (2002) Inflammation and repair of tissue. In: Slauson DO, Cooper BJ, eds. Mechanisms of Disease, 3rd ed. CV Mosby, St. Louis, MO, chap 4, pp 140-245

4. Boring L, Gosling J, Chensue SW, Kunkel SL, Farese RV Jr, Broxmeyer HE, Charo IF (1997) Impaired monocyte migration and reduced type 1 (Thl) cytokine responses in C-C chemokine receptor 2 knockout mice. J Clin Invest 100:2552-2561

5. Cardin RD, Brooks JW, Sarawar SR, Doherty PC (1996) Progressive loss of CD8 + T cellmediated control of a gamma-herpesvirus in the absence of CD4 + T cells. J Exp Med 184:863-871

6. Chomczynski P, Sacchi N (1987) Single-step method of RNA isolation by acid guanidinium thiocyanate-phenol-chloroform extraction. Anal Biochem 162:156-159

7. Cool CD, Rai PR, Yeager ME, Hernandez-Saavedra D, Serls AE, Bull TM, Geraci MW, Brown KK, Routes JM, Tunder RM, Voelker NF (2003) Expression of human herpesvirus 8 in primary pulmonary hypertension. N Engl J Med 349:1113-1122

8. Dawson TC, Beck MA, Kuziel WA, Henderson F, Maeda N (2000) Contrasting effects of CCR5 and CCR2 deficiency in the pulmonary inflammatory response to influenza A virus. Am J Pathol 156:1951-1959

9. Domachowske JB, Bonville CA, Dyer KD, Easton AJ, Rosenberg HF (2000a) Pulmonary eosinophilia and production of MIP-1 alpha are prominent responses to infection with pneumonia virus of mice. Cell Immunol 200:98-104

10. Domachowske JB, Bonville CA, Gao JL, Murphy PM, Easton AJ, Rosenberg HF (2000b) MIP-1 alpha is produced but it does not control pulmonary inflammation in response to respiratory syncytial virus infection in mice. Cell Immunol 206:1-6

11. Farmilo AJ, Stead RH, Atwood KN (2001) Fixation, In: Boenisch T, ed. Handbook of Immunochemical Staining Methods 3rd ed. DAKO Corportation, Carpinteria, pp 18-22

12. Flano E, Kim IJ, Moore J, Woodland DL, Blackman MA (2003) Differential gamma-herpesvirus distribution in distinct anatomical locations and cell subsets during persistent infection in mice. $\mathbf{J}$ Immunol 170:3828-3834

13. Harrod KS, Mounday AD, Stripp BR, Whitsett JA (1998) Clara cell secretory protein decreases lung inflammation after acute virus infection. Am J Physiol 275:L924-L930

14. Hobbs MV, Weigle WO, Noonan DJ, Torbett BE, McEvilly RJ, Koch RJ, Cardenas GJ, Ernst DN (1993) Patterns of cytokine gene expression by CD4 + T cells from young and old mice. J Immunol 150:3602-3614

15. Kurihara T, Warr G, Loy J, Bravo R (1997) Defects in macrophage recruitment and host defense in mice lacking the CCR2 chemokine receptor. J Exp Med 186:1757-1762

16. Kuziel WA, Morgan SJ, Dawson TC, Griffin S, Smithies O, Ley K, Maeda N (1997) Severe reduction in leukocyte adhesion and monocyte extravasation in mice deficient in CC chemokine receptor 2. Proc Natl Acad Sci USA 94:12053-12058

17. Lu B, Rutledge BJ, Gu L, Fiorillo J, Lukacs NW, Kunkel SL, North R, Gerard C, Rollins BJ (1998) Abnormalities in monocyte recruitment and cytokine expression in monocyte chemoattractant protein 1-deficient mice. J Exp Med 187:601-608 
18. Luster AD (1998) Chemokines - chemotactic cytokines that mediate inflammation. N Engl J Med 338:436-445

19. Maus U, von Grote K, Kuziel WA, Mack M, Miller EJ, Cihak J, Stangassinger M, Maus R, Schlondorff D, Seeger W, Lohmeyer J (2002) The role of CC chemokine receptor 2 in alveolar monocyte and neutrophil immigration in intact mice. Am J Respir Crit Care Med 166:268-273

20. Miyazato A, Kawakami K, Iwakura Y, Saito A (2000) Chemokine synthesis and cellular inflammatory changes in lungs of mice bearing p40tax of human T-lymphotropic virus type 1. Clin Exp Immunol 120:113-124

21. Peters W, Scott HM, Chambers HF, Flynn JL, Charo IF, Ernst JD (2001) Chemokine receptor 2 serves an early and essential role in resistance to Mycobacterium tuberculosis. Proc Natl Acad Sci USA 98:7958-7963

22. Rajcani J, Blaskovic D, Svobodova J, Ciampor F, Huckova D, Stanekova D (1985) Pathogenesis of acute and persistent murine herpesvirus infection in mice. Acta Virol 29:51-60

23. Ringler DJ (1997) Inflammation and repair. In: Jones TC, Hunt RD, King NW, eds. Veterinary Pathology 6th ed. Lippincott Williams \& Wilkins, Baltimore, MD, chap 5, pp 113-157

24. Rochford R, Lutzke ML, Alfmito RS, Clavo A, Cardin RD (2001) Kinetics of murine gammaherpesvirus 68 gene expression following infection of murine cells in culture and in mice. $\mathrm{J}$ Virol 75:4955-4963

25. Rollins BJ (1997) Chemokines. Blood 90:909-928

26. Sarawar SR, Lee BJ, Anderson M, Teng YC, Zuberi R, Von Gesjen S (2002) Chemokine induction and leukocyte trafficking to the lungs during murine gammaherpesvirus 68 (MHV-68) infection. Virology 293:54-62

27. Simas JP, Efstathiou S (1998) Murine gammaherpesvirus 68: a model for the study of gammaherpesvirus pathogenesis. Trends Microbiol 6:276-282

28. Stewart JP, Usherwood EJ, Ross A, Dyson H, Nash T (1998) Lung epithelial cells are a major site of murine gammaherpesvirus persistence. J Exp Med 187:1941-1951

29. Sunil-Chandra NP, Efstathiou S, Nash AA (1992a) Murine gammaherpesvirus 68 establishes a latent infection in mouse B lymphocytes in vivo. J Gen Virol 73:3275-3279

30. Sunil-Chandra NP, Efstathiou S, Arno J, Nash AA (1992b) Virological and pathological features of mice infected with murine gamma-herpesvirus 68. J Gen Virol 73:2347-2356

31. Svobodova J, Blaskovic D, Mistrikova J (1982a) Growth characteristics of herpesviruses isolated from free living small rodents. Acta Virol 26:256-263

32. Svobodova J, Stancekova M, Blaskovic D, Mistrikova J, Lesso J, Russ G, Masarova P (1982b) Antigenic relatedness of alphaherpesviruses isolated from free-living rodents. Acta Virol 26:438-443

33. Tang YW, Johnson JE, Browning PJ, Cruz-Gervis RA, Davis A, Graham BS, Brigham KL, Oates JA Jr, Loyd JE, Stecenko AA (2003) Herpesvirus DNA is consistently detected in lungs of patients with idiopathic pulmonary fibrosis. J Clin Microbiol 41:2633-2640

34. Taub DD (1996) Chemokine-leukocyte interactions. The voodoo that they do so well. Cytokine Growth Factor Rev 7:355-376

35. Traynor TR, Herring AC, Dorf ME, Kuziel WA, Toews GB, Huffnagle GB (2002) Differential roles of CC chemokine ligand 2/monocyte chemotactic protein-1 and CCR2 in the development of T1 immunity. J Immunol 168:4659-4666

36. Tripp RA, Jones L, Anderson LJ (2000) Respiratory syncytial virus G and/or SH glycoproteins modify CC and CXC chemokine mRNA expression in the BALB/c mouse. J Virol 74:6227-6229

37. Usherwood EJ, Stewart JP, Robertson K, Alien DJ, Nash AA (1996) Absence of splenic latency in murine gammaherpesvirus 68-infected B cell-deficient mice. J Gen Virol 77:2819-2825

38. Weinberg JB, Lutzke ML, Efstathiou S, Kunkel SL, Rochford R (2002) Elevated chemokine responses are maintained in lungs after clearance of viral infection. J Virol 76:10518-10523

39. Zlotnik A, Yoshie O (2000) Chemokines: a new classification system and their role in immunity. Immunity 12:121-127

Accepted for publication: January 32005 